\title{
Analisis Program PT. JICT Rumah Belajar dalam Mendukung Indonesian Sustainable Development Goals 2018
}

\author{
Hafidzah Dinda Alimuary \\ Fakultas Ilmu Komunikasi, Institut Komunikasi dan Bisnis LSPR
}

\begin{abstract}
ABSTRAK
Penelitian ini bertujuan untuk menganalisis pelaksanaan nyata program CSR Rumah Belajar di bidang pendidikan yang sebenarnya dilakukan oleh PT. Jakarta International Container Terminal (JICT) for support for Sustainable Development Goals (SDGs) 4, Quality Education. Salah satu faktor yang menentukan keberhasilan bisnis tersebut adalah kepedulian perusahaan dan rasa hormat terhadap lingkungan sekitar. Area tersebut dinamakan Corporate Social Responsibility (CSR). Penelitian ini mengambil studi kasus pada PT. JICT. Penelitian ini dilakukan melalui pendekatan kualitatif. Hasilnya, PT JICT lebih memperhatikan program Corporate Social Responsibility (CSR), JICT membangun sekolah informal dan berskala besar Rumah Belajar (RumBel). Jumlah siswa dan guru Rumah Belajar JICT sebanyak 300 orang, sehingga lulusannya dapat diandalkan, dituntut oleh sinergi aktif dan kreatif dari guru dan tim pendamping. JICT telah mengembangkan sekolah Rumah Belajar (RumBel).
\end{abstract}

Kata kunci: CSR; SDGs; Pendidikan

\section{ABSTRACT}

This study aims to analyze the actual implementation of the Rumah Belajar CSR program in the field of education actually carried out by PT. Jakarta International Container Terminal (JICT) for support for Sustainable Development Goals (SDGs) 4, Quality Education. One of the factors that determined the success of the business are corporate concern and respect for the surrounding environments. The area is called Corporate Social Responsibility (CSR). This research takes a case study at PT. JICT. This research was conducted through a qualitative approach. In result, PT JICT pay more attention to their Corporate Social Responsibility (CSR) programs, JICT has developed an informal and large-scale Learning House (RumBel) school. There are 300 JICT Learning House students and teachers, so that the graduates are reliable, demanded by the active and creative synergy of the teacher and the accompanying team. JICT has developed an informal and large-scale Learning House (RumBel) school.

Keywords: CSR; SDGs; Education

\section{PENDAHULUAN}

Keberhasilan dunia bisnis tidak hanya bertumpu kepada produk yang bagus, harga terjangkau, dan jaringan pemasaran yang canggih. Salah satu faktor yang menentukan keberhasilan bisnis tersebut adalah kepedulian perusahaan terhadap lingkungan sekitar. Area tersebut dinamakan Corporate Social Responsibility (CSR). (Kartikawangi, 2016) 
Dalam The World Business Council for Sustainable Development, CSR sebagai komitmen berkelanjutan para pelaku bisnis untuk berkontribusi dalam pembangunan ekonomi, sekaligus melakukan peningkatan kualitas pekerja dan keluarganya serta bagi komunitas lokal dan juga masyarakatnya. Berdasarkan hal tersebut, perusahaan memiliki tanggung jawab untuk mengambil peran dalam pembangunan berkelanjutan melalui usaha-usaha yang tetap sejalan dengan kepentingan pemilik saham. (Solihin, 2011, p.28)

John Elkinton (1997), mengemukakan definisi CSR adalah bahwa perusahaan menunjukkan tanggung jawab sosial melalui perhatian dalam rangka meningkatkan kualitas perusahaan (laba), masyarakat (manusia), dan lingkungan (planet). (Susanto, 2009, p. 11). Sedangkan CSR perusahaan pada dasarnya bertujuan untuk menjalankan dasar hukum dan beberapa kewajiban ekonomi. Jadi, korporasi harus melakukan hal yang benar dan bertindak dengan cara yang baik untuk menghormati masyarakat (Robbins \& Coulter, 2010).

Selain meningkatkan keuntungan, tanggung jawab sosial perusahaan juga dapat menambah nilai dalam melindungi dan mewujudkan kesejahteraan sosial bagi masyarakat sekitar, bahkan bagi masyarakat luas. Jika Corporate Social Responsibility berlaku untuk korporasi yang telah go public, maka jelaslah bahwa tanggung jawab perusahaan tidak hanya untuk pemegang saham, tetapi juga untuk masyarakat luas. (Kartikawangi, 2016)

Mengikuti regulasi yang berkembang di Indonesia. Indonesia merupakan negara yang mengharuskan perusahaan atau korporasi khususnya yang bergerak di bidang pengelolaan sumber daya alam mengeluarkan dana untuk tanggung jawab sosial perusahaan (CSR). Hal tersebut mewajibkan perusahaan untuk melakukan kegiatan CSR sebagaimana diatur dalam Undang-undang No 40 Tahun 2007 tentang Perseroan Terbatas (UU PT) dan Undang-undang No 25 Tahun 2007 tentang Penanaman Modal Asing (UU PM). Pasal 74 UU PT menyebutkan bahwa setiap perusahaan yang menjalankan kegiatannya di bidang dan / atau berkaitan dengan sumber daya alam wajib melaksanakan tanggung jawab sosial dan lingkungannya. Secara hukum, Pasal 66 ayat 2 huruf C Statuta Perseroan Terbatas Nomor 40 Tahun 2007 menyebutkan bahwa perusahaan-perusahaan di Indonesia wajib mengungkapkan tanggung jawab sosial dan lingkungannya dalam laporan keuangan tahunannya. Dengan pernyataan tersebut dalam laporan tersebut, motif perusahaan menerbitkan Laporan Keberlanjutan semakin meningkat. Awalnya hanya dua perusahaan yang menerbitkan laporan keberlanjutan pada tahun 2005. Kini, setelah satu dekade, Indonesia, dengan 60 perusahaan yang menerbitkan laporan keberlanjutan atau CSR, menjadi yang terdepan dan negara terbesar yang menerbitkan laporan tersebut hingga tahun 2014.

Pentingnya pelaksanaan program CSR ini adalah bahwa jika perusahaan tidak memperhatikan program CSR-nya maka akan menimbulkan konflik sosial. Dimana, konflik sosial dapat muncul karena kurangnya perhatian perusahaan kepada masyarakat dan lingkungan. Sementara itu, kerugian yang ditimbulkan akibat konflik akan cukup besar dan akan berdampak pada perusahaan dan lingkungan serta masyarakat. (Andraina, n.d.)

Ada banyak aspek kegiatan yang harus diperhatikan perusahaan agar dapat diterapkan dalam program CSR-nya. Diantaranya pendidikan, kesehatan, bencana alam, infrastruktur, 
kemandirian ekonomi, dan lain-lain. Dalam situasi tertentu, CSR perusahaan juga dilibatkan dalam upaya pencapaian Millennium Development Goals (MDGs). CSR lebih lanjut termasuk dalam Tujuan Global untuk Pembangunan Berkelanjutan (SDGs). (Kartikawangi, 2016)

Tujuan Pembangunan Berkelanjutan (SDGs), dengan kata lain, Tujuan Global, adalah tindakan stimulus universal untuk mengakhiri kemiskinan, melindungi bumi dan memastikan bahwa semua orang dapat menikmati kehidupan yang damai dan sejahtera. 17 Tujuan ini dibangun atas keberhasilan program United Nations Development Program (UNDP) sebelumnya, Tujuan Pembangunan Milenium, sambil berkembang di beberapa bidang baru seperti perubahan iklim, ketimpangan ekonomi, inovasi, konsumsi berkelanjutan, perdamaian dan keadilan, di antara prioritas lainnya. Tujuan-tujuan tersebut saling berhubungan lebih sering dikaitkan dengan yang lain. (undp.org)

Meningkatkan kualitas masyarakat dapat berarti membantu masyarakat mencapai kesadaran diri dalam berbagai bentuk. Bentuk-bentuk ini setidaknya untuk mencapai pemenuhan hak asasi manusia. Salah satu hak dasar tersebut adalah pemenuhan kebutuhan pendidikan. Salah satu poin dari SDGs tersebut adalah Pendidikan Berkualitas, dimana kualitas pendidikan sangat dibutuhkan untuk menunjang kehidupan masyarakat. SDG 4 adalah memastikan kualitas pendidikan yang inklusif dan merata serta mendorong kesempatan belajar seumur hidup bagi semua (undp, n.d.)

Zamroni (2009), menjelaskan bahwa berbagai ketimpangan pendidikan di tengah masyarakat telah terjadi, antara lain: (a) ketimpangan antara kualitas hasil pendidikan dan kualifikasi tenaga kerja yang dibutuhkan; (b) ketimpangan kualitas pendidikan yang terjadi akibat ketidakmampuan ekonomi. Hal tersebut disebabkan mahalnya biaya pendidikan, dan terbatasnya sarana dan prasarana pendidikan. (Mulyandari, 2010)

Kurangnya kesadaran masyarakat akan pentingnya pendidikan dan juga terbatasnya akses bagi anak-anak kurang mampu, menjadikan pendidikan di Indonesia memiliki pola yang cukup kompleks. Peran pemerintah, masyarakat, dan beberapa pihak terkait sangat dibutuhkan dalam pengembangan pendidikan. Menteri Pendidikan Nasional 2014, Mohammad Nuh mengatakan, pendidikan merupakan tanggung jawab semua pihak, padahal negara mengamanatkan penyelenggaraan pendidikan. Partisipasi ini menuntut dari masyarakat, BUMN, bahkan swasta. (pikiranrakyat)

Oleh karena itu, semua pelaku usaha memiliki peran dan tanggung jawab dalam meningkatkan kesejahteraan masyarakat dalam pendidikan melalui program CSR-nya, karena dalam berbagai tingkatan kehidupan, pendidikan merupakan hal penting dan dapat memberikan banyak kesempatan untuk meningkatkan kualitas hidup.

Di Indonesia, PT Jakarta International Container Terminal (JICT) kembali mendapatkan penghargaan program CSR terbaik untuk kategori SDGs 4 atau program pendidikan berkualitas, dalam Indonesian Sustainable Development Goals Award (ISDA) 2018. Dalam ajang ini, JICT berhasil meraih dua penghargaan yaitu emas untuk program Rumah Belajar 
(RumBel) dan 'perak' untuk program Green Dock School. Prestasi istimewa ini sekaligus menjadikan JICT sebagai perusahaan yang meraih juara 2 tahun berturut-turut. (beritasatu.com)

PT JICT lebih memperhatikan program-program Corporate Social Responsibility (CSR), demikian pula CSR dianggap sebagai inovasi dalam pengelolaan bisnis sehingga dapat mencapai nilai strategis sepenuhnya bahkan ada organisasi yang percaya bahwa CSR melindungi dari efek negatif dari krisis ekonomi (Janssen, Sen \& Bhattacharya, 2015).

Damanpour dan Gopalakrishnan (2001) mendefinisikannya sebagai "adopsi ide atau perilaku baru dalam organisasi". CSR berkontribusi dan mendorong inovasi dalam tiga cara: (a) inovasi yang dihasilkan dari dialog dengan berbagai pemangku kepentingan baik internal maupun eksternal perusahaan; (b) mengidentifikasi peluang bisnis baru yang timbul dari tuntutan sosial dan produk lingkungan serta proses yang lebih efisien atau bentuk bisnis baru yang ditujukan pada dasar piramida, yang dibentuk oleh orang-orang dengan sumber daya yang lebih sedikit (Prahalad \& Ramaswamy, 2004); (c) menciptakan tempat dan cara kerja yang lebih baik yang mendorong inovasi dan kreativitas, seperti yang didasarkan pada partisipasi dan kepercayaan karyawan yang lebih besar di dalamnya (Hernandez \& Sanchez, 2012).

Kehadiran program CSR di masyarakat merupakan tanggung jawab moral perusahaan terhadap masyarakat atau masyarakat sekitar wilayah kerja dan operasionalnya. Oleh karena itu, penting bagi perusahaan untuk mengedepankan program-program konkrit seperti Community Development (CD). Beberapa program CD antara lain meningkatkan kemampuan masyarakat untuk menemukan alternatif ekonomi dalam jangka panjang; meningkatkan kualitas hidup masyarakat, baik dalam dimensi ekonomi, sosial, dan budaya; memperkuat institusi lokal yang mampu menjadi ujung tombak pertumbuhan inisiatif lokal; dan kemandirian masyarakat, baik di bidang politik, ekonomi dan budaya. (Mustofa, 2012) Beritasatu.com juga melaporkan bahwa Direktur Utama JICT Gunta Prabawa mengatakan, sebagai terminal peti kemas terbesar di Indonesia, pihaknya terus berupaya memberikan kontribusi aktif kepada masyarakat di wilayahnya, Jakarta Utara.

Ia juga menyampaikan bahwa program RumBel dan Green Dock School diharapkan mampu memberikan penjaminan mutu pendidikan yang inklusif dan merata, sehingga tercapainya SDG ke 4. (undp, n.d.) mengingat pentingnya kesetaraan dalam pendidikan bagi warga sekitar untuk kehidupan yang lebih baik. Menurutnya, melalui program tanggung jawab sosial perusahaan, JICT secara tidak langsung telah meningkatkan kesempatan belajar anak di wilayah Jakarta Utara secara berkelanjutan.

Dalam programnya selama 10 tahun terakhir, JICT telah mengembangkan sekolah informal dan berskala besar Rumah Belajar (RumBel). Jumlah siswa dan guru Rumah Belajar JICT sebanyak 300 orang, sehingga lulusannya dapat diandalkan, dituntut oleh sinergi aktif dan kreatif dari guru dan tim pendamping. 
Menurut Corporate Affairs Manager Indira Lestari dalam keterangannya RumBel merupakan sekolah informal dengan latar belakang siswa yang motivasi sekolahnya rendah, namun harus tetap memiliki kurikulum yang handal. Ini menjadi tantangan bagi kami dalam mendukung SDGs.

JICT memiliki Program Belajar di Rumah (RumBel) untuk penyediaan pendidikan bagi anak putus sekolah. Program Rumah Belajar merupakan wadah yang difasilitasi oleh JICT kepada anak-anak putus sekolah di sekitar kantor untuk mendapatkan stud. Program RumBel memiliki tiga tempat sentral di sekitar Jakarta Utara, yaitu di Kecamatan Tanjung Priok, Cilincing, dan Koja, masing-masing kelas sentral terdapat beberapa kelas kecil yang menunjang beberapa proses pembelajaran.

Selain itu program Green Dock School, menurut Direktur Utama PT JICT, Gunta Prabawa menyampaikan melalui CSR JICT yang difokuskan pada bidang pendidikan, kesehatan, lingkungan dan budaya. Lebih dari 25.000 masyarakat Jakarta Utara, khususnya di Kecamatan Tanjung Priok, Cilincing dan Koja telah merasakan manfaat dari keberadaan CSR JICT. dimana Green Dock School of JICT menargetkan perbaikan sekolah hijau dan pendidikan lingkungan di Jakarta Utara.

Gunta Prabawa juga menyampaikan bahwa tujuan mereka dalam fokus program CSR bidang pendidikan di Jakarta Utara karena PT JICT ingin mendukung pencapaian tujuan pembangunan berkelanjutan (SDGs) di tahun 2030. "Kami ingin masyarakat Jakarta Utara tumbuh bersama JICT Kita care, we share, JICT for Indonesia."

Dalam hal ini terlihat bahwa PT JICT berhasil melaksanakan program CSR terkait dengan SDG, dan menarik untuk dianalisa bagaimana program CSR JICT, Rumah Belajar untuk mendukung tujuan nomor empat dalam Tujuan Pembangunan Berkelanjutan (SDGs), kualitas pendidikan.

Artikel ini akan membahas bagaimana Penelitian ini untuk mengetahui sejauh mana PT JICT telah melakukan pengembangan masyarakat dan peningkatan ekonomi masyarakat dalam melaksanakan CSR dan mencapai pemenuhan pembangunan berkelanjutan global (SDGs) 4, Quality Education. Penelitian ini akan menjawab pertanyaan mengenai peran seperti apa yang dilakukan oleh CSR PT JICT dalam implementasi dalam sektor pendidikan, menganalisa bagaimana tujuan program CSR PT JICT, yaitu Rumah Belajar, dapat berpengaruh di masyarakat, dan apakah dengan adanya Rumah Belajar, PT JICT ikut membantu dalam pemenuhan SDGs no. 4, Quality Education.

\section{METODOLOGI PENELITIAN}

Artikel ini dilakukan melalui pendekatan kualitatif. Pendekatan kualitatif dipilih karena mampu memberikan pemahaman yang mendalam dan rinci tentang suatu peristiwa atau fenomena sosial. ketika melakukan penelitian kualitatif, itu menciptakan bentuk konsep- 
konsep baru atau menyempurnakan konsep yang didasarkan pada data. Pembentukan konsep merupakan bagian integral dari analisis data dan dimulai selama pengumpulan data. Jadi, konseptualisasi adalah cara untuk mengatur dan memahami data. (Neuman, 2014)

Strategi yang digunakan dalam penelitian ini adalah studi kasus. Penelitian studi kasus memverifikasi banyak fitur dari beberapa kasus. Kasus tersebut dapat berupa individu, kelompok, organisasi, gerakan, peristiwa, atau unit geografis. Data yang digunakan dalam kasus ini sangat detail, variatif, dan ekstensif. Itu bisa fokus pada satu titik waktu atau durasi waktu. (Neuman, 2014)

Dalam penelitian ini studi kasus mengarah pada gambaran secara detail dan mendalam mengenai potret kondisi apa yang sebenarnya terjadi sesuai dengan yang ada di lapangan, yaitu implementasi CSR di PT JICT dalam rangka mendukung Program Tujuan Pembangunan Berkelanjutan.

Peneliti mengekstraksi informasi dari brosur perusahaan, laporan program tahunan, dan artikel koran atau majalah, bersama dengan observasi langsung ke lapangan dengan menggabungkan hasil wawancara. Tujuannya adalah untuk mendapatkan banyak perspektif tentang suatu organisasi, situasi, peristiwa, atau proses pada suatu waktu.

\section{HASIL DAN PEMBAHASAN}

Situasi pendidikan di Indonesia saat ini, khususnya di wilayah Jakarta Utara, masih di bawah rata-rata. Hal ini terlihat dari masih minimnya kesadaran masyarakat tentang pentingnya pemenuhan pendidikan pada anak, hal ini tercermin dari masih banyaknya anak putus sekolah di daerah tersebut.

Dari data yang ada terlihat bahwa tingkat putus sekolah yang dialami warga Jakarta Utara cukup tinggi. Dalam wawancara yang telah dilakukan terdapat beberapa penyebab anak menjadi putus sekolah, antara lain permasalahan yang dihadapi di sekolah seperti bullying, hingga ketidakmampuan masyarakat untuk melanjutkan sekolah baik dari segi ekonomi maupun kemampuan individu diri.

Dengan angka putus sekolah yang tinggi ini, seiring dengan meningkatnya angka kriminalitas di Jakarta Utara, khususnya Tanjung Priok, Cilincing, Koja. Dimana anak-anak putus sekolah akhirnya turun ke jalan untuk sekedar mengisi waktu luang atau bahkan mencari uang. Namun karena latar belakang pendidikan yang rendah, mereka cenderung melakukan hal-hal yang melanggar hukum, seperti mengemis, mencopet, menyita barang dalam peti kemas yang lalu lalang bahkan mungkin terlibat dalam peredaran obat-obatan terlarang.

Hal ini juga menyebabkan rendahnya Indeks Pembangunan Manusia Jakarta Utara meskipun wilayahnya termasuk kawasan industri terbesar di Jakarta. Hal ini sangat disayangkan oleh PT JICT, salah satu pelaku industri di Jakarta Utara.

Melihat situasi di sekitar perusahaan, PT JICT bekerjasama dengan LSM Jala Samudra Mandiri membuat program CSR bertajuk Rumah Belajar. Dimana dari hasil wawancara di atas, Rumah Belajar merupakan sarana belajar mengajar yang disediakan oleh PT JICT untuk mendukung masyarakat sekitar dalam memenuhi kebutuhan pendidikannya. 
Rumah Belajar merupakan program CSR PT JICT di bidang pendidikan, program ini telah berjalan selama 10 tahun, dimana pada awalnya program ini tidak dilakukan dengan mudah. Diketahui bahwa dalam wawancara, program ini awalnya dilakukan dengan melibatkan beberapa fasilitator yang turun ke jalan dan memberikan penjelasan terkait program kepada anak-anak yang terdampar di jalanan.

Fasilitator membantu mengkomunikasikan bantuan yang ingin diberikan kepada masyarakat sekitar, berupa pentingnya pendidikan, bagaimana minimnya pendidikan dapat berkontribusi pada peningkatan angka kriminalitas di daerah, dan lain-lain. Upaya yang dilakukan membuahkan hasil, masyarakat mulai menyadari pentingnya pendidikan dan program Rumah Belajar diterima oleh masyarakat.

Dengan perkembangan program Rumah Belajar ini, saat ini Rumah Belajar memiliki 3 kelas utama, kelas utama ini berlokasi di daerah Tanjung Priok, Cilincing, Koja, dimana kelas utama memiliki beberapa kelas yang jauh. Kelas Jauh adalah kelas kecil yang dibangun untuk menjangkau daerahdaerah terpencil agar mereka tetap bisa mendapatkan fasilitas dari Rumah Belajar tanpa harus jauh-jauh datang ke kelas utama.

Di kelas utamanya, Rumah Belajar menyediakan beberapa fasilitas belajar mengajar. Mata pelajaran yang dipelajari bermacam-macam, seperti merancang menggunakan aplikasi photoshop, pendidikan dasar pengoperasian komputer dan juga bahasa inggris. Sedangkan untuk kelas-kelas jauh yang tersebar di pelosok hanya terdapat fasilitas untuk pembelajaran dasar, seperti pembelajaran menulis, membaca, dan beberapa kurikulum SD, SMP, dan SMA.

Bagi guru yang mengikuti pemerataan paket $\mathrm{A}, \mathrm{B}$, dan $\mathrm{C}$, mereka akan dapat mengikuti tes sesuai kemampuan masing-masing siswa dan jika sudah mencukupi, JICT akan memfasilitasi anak untuk mengikuti tes tersebut.

Dalam implementasinya, selain LSM Jala Samudra Mandiri, PT JICT juga terlibat penuh dalam program Rumah Belajar. Diketahui bahwa PT JICT terus memantau jalannya program dan juga terus mengumpulkan laporan lapangan untuk dapat melihat dan menilai perkembangannya.

Menurut hasil wawancara, saat ini permasalahan tersebut belum sepenuhnya terpenuhi, karena memang masih banyak daerah yang belum tersentuh, saat ini JICT hanya dapat membantu masyarakat terdekat JICT yaitu Tj Priok, Cilincing, dan Koja, yang kami sebut di wilayah jalur 1. Bisa dibilang sudah terpenuhi, setidaknya dari tahun 2010 lebih dari 10.000 anak telah tertolong oleh JICT dan itu saja belum cukup, masih banyak anak diluar sana yang belum tertolong.

Untuk itu, JICT melihat program ini sebagai investasi jangka panjang. Dalam wawancaranya diketahui bahwa CSR itu sendiri merupakan manfaat jangka panjang, jadi bagaimana kita bisa mendapatkan dukungan dari masyarakat melalui bantuan yang kita berikan kepada masyarakat. Sebenarnya banyak sekali dukungan dari masyarakat sendiri kepada JICT dalam bentuk dukungan non finansial. Namun jika JICT membangun community development dalam bentuk pendidikan atau kesehatan atau pemberdayaan lingkungan, misalnya ketika anak-anak di sekitar Jakarta Utara yang putus sekolah berkembang menjadi kriminalitas, dengan memberikan pendidikan yang baik kemungkinan besar nantinya akan mendukung. JICT kedepannya, jadi saya bilang CSR itu investasi jangka panjang.

Saat ini program Rumah Belajar telah menjadi salah satu sarana pendidikan yang diandalkan oleh warga kurang mampu, dimana banyak warga yang terlibat dalam pelaksanaan program Rumah Belajar. Seperti diketahui dari wawancara, saat ini anak-anak di sana merasa Rumah Belajar ini adalah rumah mereka. 
Sehingga yang tidak mau datang bisa nyaman dan rajin dalam menjalankan aktivitas di Rumah Belajar itu sendiri. Dan dari pihak warga, banyak warga yang terlibat dalam pelaksanaannya, seperti memberikan pelajaran dasar bagi anak-anak di sana, hingga menyuplai kebutuhan dasar Rumah Belajar.

Padahal, saat ini ada warga yang meminta dibuatkan kelas-kelas jauh dari Pusat Pembelajaran agar bisa mendapatkan fasilitas pendidikan yang memadai di daerahnya yang mudah dijangkau, dari sini terlihat kesadaran masyarakat akan kebutuhan pendidikan mulai meningkat. meningkat, dan program Rumah Belajar PT JICT ikut ambil bagian dalam kemajuan ini.

Mengacu pada teori yang digunakan, dimana CSR merumuskan Triple Bottom Lines (TBL) atau tiga faktor utama pengoperasian perusahaan dalam kaitannya dengan lingkungan dan manusia yaitu faktor manusia dan masyarakat (people), faktor ekonomi dan keuntungan (profit), dan lingkungan. faktor (planet) (Elkington dalam Hardiansyah, 2008).

Dimana disini terlihat bagaimana PT JICT melaksanakan program CSR bertajuk Rumah Belajar yang melibatkan masyarakat, membantu masyarakat dalam mewujudkan kesejahteraan manusia, serta turut membantu memajukan lingkungan masyarakat.

Dan dengan adanya program Rumah Belajar tentunya dapat membantu dalam pembangunan masyarakat yang berkelanjutan, dimana program tersebut bermanfaat bagi masyarakat untuk membentuk kesadaran di masyarakat. Dan dalam kegiatannya, Rumah Belajar memiliki interaksi aktif antara pekerja sosial dan masyarakat yang terlibat dalam proses perencanaan, pelaksanaan, pemantauan dan evaluasi program pembangunan kesejahteraan sosial atau usaha kesejahteraan sosial, seperti yang tertulis dalam Suharto (2005).

Dan juga dalam Payne (dalam Ambadar, 2008) disebutkan Community Development (COMDev) memiliki fokus pada upaya membantu anggota masyarakat yang memiliki minat yang sama untuk bekerja sama, dengan mengidentifikasi kebutuhan bersama kemudian melakukan kegiatan bersama untuk memenuhi kebutuhan tersebut. Hal ini terlihat dari kontribusi masyarakat terhadap pelaksanaan program Rumah Belajar dan turut mendukung terlaksananya kegiatan di sana.

\section{SIMPULAN}

Kurangnya kesadaran akan pentingnya pendidikan membuat masyarakat seakan meremehkan kebutuhan akan pendidikan, padahal pendidikan merupakan hal yang penting dilakukan guna meningkatkan kesejahteraan hidup. Program Pembangunan Perserikatan Bangsa-Bangsa (UNDP) telah mencetuskan beberapa tujuan, salah satunya adalah Pendidikan Kesetaraan, dimana kesetaraan pendidikan dianggap sebagai isu penting dalam masyarakat dunia sehingga perlu dilakukan penyadaran akan masalah ini.

Di Indonesia bahkan Ibukota Jakarta masih kurang mementingkan kebutuhan pendidikan masyarakatnya, terlihat dari masih tingginya angka kemiskinan dan masih banyaknya angka putus sekolah yang berakibat pada menurunnya kualitas hidup di Jakarta. Jakarta Utara merupakan salah satu kota dengan tingkat kemiskinan yang tinggi, dengan hal tersebut akan muncul beberapa permasalahan baru seperti kriminalitas, peredaran narkoba dan lain-lain. 
Program CSR merupakan salah satu metode yang digunakan dalam menyelesaikan permasalahan terkait kesetaraan pendidikan, mengingat banyaknya perusahaan besar di Jakarta dinilai semakin memudahkan untuk menjangkau masyarakat sekitar perusahaan. Program CSR di bidang pendidikan dinilai penting, karena selain untuk memenuhi kebutuhan masyarakat, program juga dilakukan untuk meningkatkan kesejahteraan dan status sosial masyarakat.

PT JICT membuat program Corporate Social Responsibility (CSR) bekerja sama dengan LSM Jala Samudra Mandiri bertajuk Rumah Belajar sebagai upaya untuk memenuhi kebutuhan pemerataan pendidikan di kawasan Jakarta Utara.

PT Jakarta International Container Terminal (JICT) sangat prihatin dengan permasalahan yang terjadi di masyarakat, dimana minimnya pemenuhan kesetaraan pendidikan yang berakibat pada kejahatan seperti perampokan, perampasan kontainer, bahkan penyebaran narkotika dan narkoba. Dan di sini JICT ikut bertanggung jawab untuk menyediakan fasilitas pendidikan yang berkelanjutan kepada individuindividu tersebut untuk dapat mengenyam pendidikan agar bisa mendapatkan kehidupan yang lebih baik, dan tentunya menciptakan lingkungan masyarakat yang lebih baik pula.

Upaya pemenuhan pendidikan yang diberikan PT JICT melalui program CSR-nya yaitu program Rumah Belajar terbukti telah membantu pemerintah Indonesia dalam memenuhi salah satu Tujuan Pembangunan Berkelanjutan (SDGs) yaitu Kesetaraan Pendidikan, dimana JICT selain berperan sebagai peran aktif dalam melaksanakan kegiatannya secara keseluruhan, juga dapat tercermin dari beberapa penghargaan yang diperoleh dari berjalannya program ini, salah satunya adalah penghargaan dari Indonesia Sustainable Development Goals Award yang dalam hal ini berarti JICT diakui berpartisipasi dalam pemenuhan SDGs.

\section{DAFTAR PUSTAKA}

Ambadar, J. (2008). CSR dalam Praktik di Indonesia. Elex Media Komputindo.

Andraina, S., \& Awza, R. (2014). Aktivitas Corporate Social Responsibility (CSR) Sebagai Upaya dalam Meningkatkan Citra Perusahaan (Studi Pada PT Energi Mega Persada Bentu \& Korinci Baru di Pekanbaru). Jurnal Online Mahasiswa (JOM) Bidang Ilmu Sosial dan Ilmu Politik, 1(1).

Damanpour, F., \& Gopalakrishnan, S. (2001). The dynamics of the adoption of product and process innovations in organizations. Journal of Management Studies, 38(1), 45-65. https://doi.org/10.1111/1467-6486.00227

Hidayat, F. (2018, September 7). JICT Raih 2 Penghargaan ISDA Award 2018. BeritaSatu. https://www.beritasatu.com/ekonomi/509277/jict-raih-2-penghargaan-isda-award-2018

Janssen, C., Sen, S., \& Bhattacharya, C. B. (2015). Corporate crises in the age of corporate social responsibility. Business Horizons, Emerging Issues in Crisis Management, 58(2), 183-192. https://doi.org/10.1016/j.bushor.2014.11.002 
Kartikawangi, D. (2017). Symbolic convergence of local wisdom in cross-cultural collaborative social responsibility: Indonesian case. Public Relations Review, 43(1), 3545. https://doi.org/10.1016/j.pubrev.2016.10.012

Mulyandari, R. H. S., Swastomo, W., Wibowo, C. T., \& Situmean, I. V. O. (2010). Implementasi CSR dalam Mendukung Pengembangan Masyarakat melalui Peningkatan Peran Pendidikan. Proceedings of Bogor Agricultural University's seminars.

Neuman, W. L. (2014). Social Research Methods: Qualitative and Quantitative Approaches. Pearson Education.

Pikiran Rakyat Online. (2010, September 26). Pendidikan Tanggung Jawab Semua Pihak. Pikiran Rakyat Online. http://www.pikiran-rakyat.com/node/123221

Prahalad, C. K., \& Ramaswamy, C. (2004). Co-creating unique value with customers. Strategy \& Leadership, 32(3), 4-9. https://doi.org/10.1108/10878570410699249

Solihin, I. (2011). Corporate Social Responsibility: From Charity to Sustainability. Salemba Empat.

Susanto, A. B. (2009). Reputation-Driven Corporate Social Responsibility (Pendekatan Strategic Management Dalam CSR). Esensi.

UNDP. (n.d.). Sustainable Development Goals. United Nations Development Programme. http://www.undp.org/content/undp/en/home/sustainable-development-goals.html 